\title{
Prediction of Talent Demand in Air Transportation Industry-Taking Yunnan as an Example
}

\author{
Jiaoyan Tang ${ }^{1}$ and Xinyou $\mathrm{Liu}^{2, *}$ \\ ${ }^{1}$ School of Humanities and Art, Yunnan Communications Vocational and Technical College, Kunming, 650500, China \\ ${ }^{2}$ Kunming Branch, Yunnan Dianzhong Water Diversion Project Construction Administration Bureau, Kunming, 650500, \\ China \\ *Corresponding author: E-mail: xyliu1981@163.com
}

\begin{abstract}
The scientific prediction of the future demand for air transportation talents is the basis of air transportation talent training planning. Based on the close relationship between air transportation employment and air passenger turnover, and the trend continuity of air passenger turnover, the talent density, trend extrapolation and regression analysis method were comprehensively used to quantitatively predict air transportation specialized talents in 2030 and 2040. The results showed that the employment number of air transportation in Yunnan Province would increase greatly in the future, and the talent density would continue to improve. Besides, the demand for air transportation specialized talents would also increase significantly. Currently, the enrollment scale of air transportation related majors in Yunnan colleges and universities basically meets the needs, while the structure of specialized talents in air transportation industry should be optimized.

Keywords: Air transportation; Talent demand prediction; Regression analysis; Trend extrapolation; Yunnan

\section{INTRODUCTION}

Air transportation serves as a fast pipeline for economic development because it can accelerate the flow of production factors and optimize resource allocation in economic activities [1]. The unique geographical position

prediction of vocational education in China should start to establish talent demand prediction system [4]. Establishing the relationship between talent demand and Yunnan air transportation development planning is conducive to improving the accuracy and pertinence of prediction, and providing a scientific basis for air transportation talent training planning.
\end{abstract} in Yunnan determines that it plays an irreplaceable pivotal role in radiating south Asia and southeast Asia in the national "Belt and Road Initiative" strategy. Simultaneously, the special terrain with mountains accounting for $94 \%$ of the province's land area determines that air transportation plays an important role in the whole transportation network. In order to accelerate the transportation development in Yunnan, the state has issued the "comprehensive transportation development plan for the radiation center in south and southeast Asia (2017-2030)", which includes a large number of major transportation development projects in Yunnan. As the key transportation network, Yunnan air transportation will usher in accelerated development in the future. It is the basic guarantee to promote the healthy development of the air transportation industry to do a good job in the air transportation development planning and talent training planning at the same time. The research shows that the demand for talents in the transportation industry in Yunnan Province will increase in varying degrees in the future, and there is still a certain growth space for the enrollment scale of transportation majors, among which the demand for talents in the air transportation industry will grow the fastest [2-3]. Talent demand prediction is the basis for making talent development planning decisions scientifically in the future. In the future, talent demand

\section{DEVELOPMENT TREND IN YUNNAN AIR TRANSPORTATION INDUSTRY}

Yunnan is a province with a large number of airports and a strong demand for air transportation market. In terms of location conditions, Yunnan borders Vietnam, Laos and Myanmar, and is adjacent to Thailand, Cambodia, India, Bangladesh, etc. With the construction of "radiation center for south and southeast Asia", Yunnan will transform from the end of the national transportation into a transportation hub for south and southeast Asia, and become a transportation radiation center with a large market of 3.5 billion people. From the perspective of transportation demand in Yunnan Province, the unique terrain conditions, rich tourism resources and people's demand for convenient transportation have prompted Yunnan Province to establish the development policy of "taking air transportation as the guide". As a province with large tourism resources, Yunnan's tourism development drives the rapid development of air transportation industry, and aviation related tourism projects are gradually rising at the same time.

By the end of 2020, Yunnan has built 20 civil transport airports. According to the air transportation development 
plan, Yunnan will also plan to build more than 50 general airports by 2030, with routes covering most remote counties and regions in the province. The advantages of airport resources in the province will gradually form a cluster effect to help the development of Yunnan aviation industry.

\section{COMPARISON AND SELECTION OF PREDICTION METHODS}

\subsection{Review on prediction methods}

From the existing research on the demand prediction of vocational skills, the prediction methods are mainly divided into two categories. One is the prediction method based on causal analysis of talent demand in functional departments and social service companies. For example, quantitative prediction was made on the basis of qualitative causality analysis in the national traffic talent prediction in 1983 due to the lack of historical data and experience. Based on the internal and external development of the forecast object, the standardized model of talent structure was determined, and then the quantitative prediction model was established. According to the nature and functions of different units, the reasonable positions, number of talents, professional structure and educational background required by them were analyzed and determined, thus achieving talent demand prediction [5]. He Qianqian predicted the total talent demand in characteristic years such as 2020 and 2025 by analyzing the current situation of talent resources in transportation industry in Henan Province [6]. The advantage of causal analysis prediction method is that it is not dependent on historical data, and the key is analysis. It is suitable for prediction objects with strong planning or relatively single influencing factors. Its disadvantage is that the workload of system analysis is heavy, and the prediction results are greatly affected by human cognitive factors. For the prediction objects with complex influencing factors, it is difficult to ensure the reliability and accuracy of the prediction results.

The other is the prediction method based on mathematical model. For example, the density calculation method and mathematical model were used to predict "the strategic research on the transportation specialized talents demand prediction and transportation education development in 2015" and "the strategic research on the guarantee of human resources and intellectual support for transportation development" [7-8]. Through the mathematical model, the total number of employees and talent density in the transportation industry in the target year were inferred, and then the number of transportation specialized talents was calculated. $\mathrm{Yu}$, et al. studied the development trend and evolution mode of transportation talents in China by establishing the system dynamics model of transportation talents, and then predicted the talent demand [9]. Ren, et al. obtained the correlation between the quantity of transportation talents and various influencing factors by analyzing the grey system theory, and established the multiple linear regression prediction model and grey prediction model for the demand prediction of transportation talents [10]. Guo, et al. used triangular fuzzy numbers to determine the fuzzy weight of each single prediction in the combined prediction method, and established a fuzzy combined prediction model of logistics talent demand based on the minimum prediction error value as the objective function [11].

\subsection{Selection of prediction methods}

Developing and utilizing a more reasonable talent demand prediction model and continuously strengthening its supporting role in the scientific planning of vocational education are of great significance for talent demand prediction in the industry and the guidance of running vocational colleges [12]. Choosing the prediction method suitable for the research object is the key to improve the prediction accuracy. The selection of prediction methods should comprehensively consider the prediction objects characteristics, prediction time period, basic data, etc. From the perspective of the prediction object, specialized talents in the air transportation industry are part of the employment with strong professional skills in the air transportation industry. The employment of air transportation is closely related to factors such as navigation mileage, passenger turnover, cargo turnover, construction investment, scientific and technological progress, etc. With regard to basic data, air transportation statistics can be obtained from "China statistical yearbook" and "Yunnan statistical yearbook". Therefore, the demand for air transportation specialized talents in Yunnan has the conditions for quantitative prediction, and the prediction method based on mathematical model can be adopted.

Specialized talents in the air transportation industry can be calculated by the employment of the air transportation industry and its talent density method. For the employment prediction in the air transportation industry, a regression analysis model can be established by single or multiple factors with relevant factors such as air transport mileage, passenger turnover, cargo turnover and construction investment, respectively. The fitting effect of each regression analysis formula can be compared, and the best fitting effect can be selected as the prediction model. Air transportation related factors develop with the development of social economy, which is a gradual process with strong trend continuity, and can be predicted by trend extrapolation method.

\section{CONSTRUCTION OF PREDICTION MODEL}

\subsection{Talent density method}

The number of air transportation specialized talents can be obtained through the analysis on the number of air 
transportation employment and talent density. The calculation formula is as follows:

$$
y_{z}=y_{j} \times k
$$

Among them, $y_{z}$ is the number of transportation specialized talents; $y_{j}$ is the number of transportation employment; $k$ is the talent density coefficient, and its value ranges from 0 to 1 .

\subsection{Regression analysis method}

Regression analysis is a commonly used statistical method. When there is only one dependent variable $y$ and one independent variable $x$, the correlation is called unary regression analysis. When there are two or more independent variables, it is called multiple regression analysis. If the regression equation obtained by regression analysis is linear with respect to unknown parameters, it is called linear regression analysis, otherwise it is called nonlinear regression analysis. This study mainly introduces the linear regression analysis method used this time.

The basic steps of regression analysis are as follows: (1) collect data. The quantity and accuracy of historical data directly affect the results of regression analysis. (2) Set the regression equation. The appropriate regression equation was selected according to the law between independent variables and dependent variables. (3) Determine the regression coefficient. The known data were substituted into the established regression equation, and the regression coefficients were calculated by the least square method to determine the regression equation. (4) Carry out correlation test. Correlation test is to test the reliability of the established regression equation that can represent the correlation between independent variables and dependent variables. Generally, the correlation coefficient test method is used.

\subsection{Trend extrapolation method}

There is usually continuity in the course of development. Therefore, it is the theoretical basis of trend extrapolation to predict the rule of future development and change from the history and current development trend of things.

There are two preconditions for trend extrapolation. First, there is no major change in the factors influencing the development of things, and the overall change trend in the development of things is sustainable. Second, the development process of things is gradual rather than jumping (i.e., the development process of things is stable). Air transportation mileage, passenger turnover, cargo turnover, construction investment, etc., are closely related to the social and economic development of air transportation demand, and their influencing factors are gradual and sustainable. Therefore, it is suitable for trend extrapolation prediction method.

Trend extrapolation prediction methods are divided into linear trend extrapolation prediction methods and curve trend extrapolation prediction methods. In practical application, the least square method or fitting method can be used to determine the parameters of the prediction model, and the fitting accuracy can be characterized by correlation coefficient. When the prediction accuracy is satisfied, the linear trend extrapolation prediction method or conic trend extrapolation prediction method is generally preferred.

\section{PREDICTION RESULTS ANALYSIS}

\subsection{Employment demand prediction}

Air employment is positively correlated with civil aviation route mileage, air transportation passenger and cargo turnover and airport construction investment. Referring to "Yunnan statistical yearbook", the regression analysis was conducted between the air employment and the air route mileage, air transportation passenger and cargo turnover, and airport construction investment from 1999 to 2018. It was found that the correlation between the air employment and air transportation passenger turnover was the best. It was appropriate to take the air transportation passenger turnover as the independent variable and use the regression analysis method to predict the air employment. According to the regression relationship between air service employment and air passenger turnover (Fig. 1), the regression relationship between air transportation employment and air passenger turnover is as follows:

$$
\mathrm{y}=164.51 x-2240.1
$$

In the equation, $\mathrm{y}$ is the air employment; $\mathrm{x}$ is the air passenger turnover. The fitting correlation coefficient R2 of regression relationship between air transportation employment and air passenger turnover is 0.9494, indicating a significant correlation between the two. 


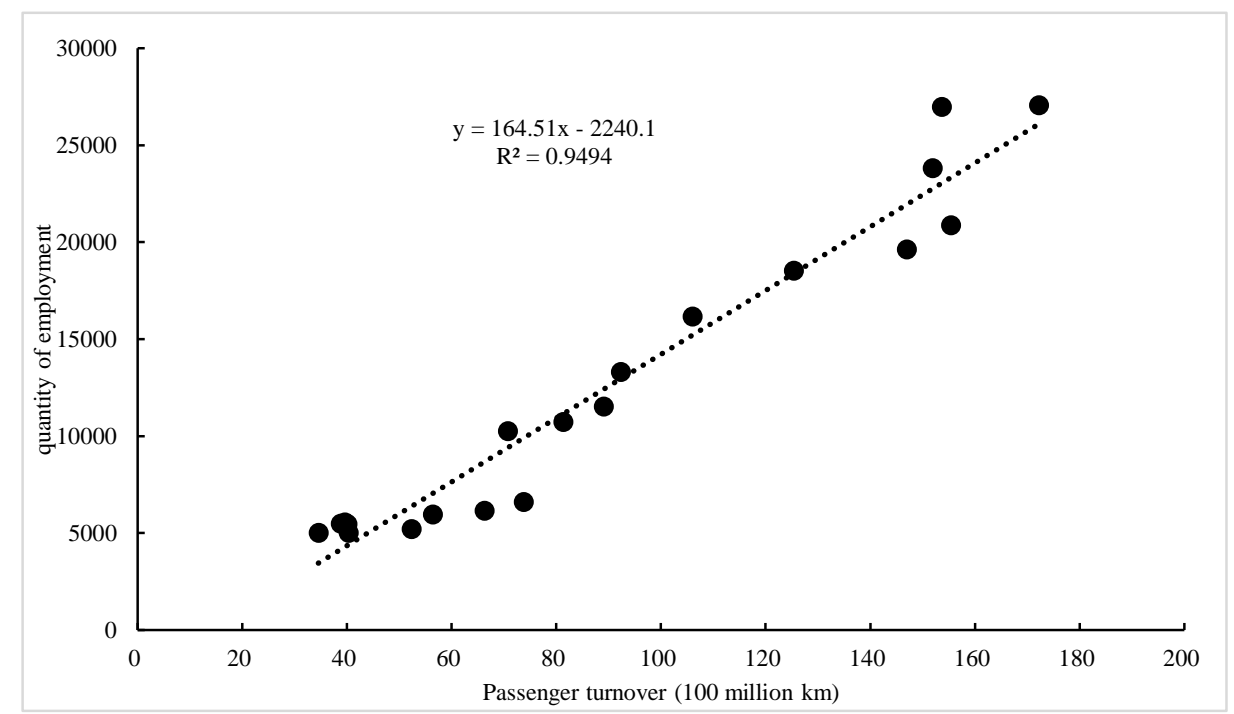

Figure 1. Regression relationship between air transportation employment and air passenger turnover

In order to predict the air service employment in a certain period in the future, it is necessary to analyze and predict the independent variable air passenger turnover. Referring to "Yunnan statistical yearbook", the air passenger turnover showed a steady growth trend in general from 1978 to 2018, showing good continuity, and thus the trend extrapolation method should be used for prediction. According to the trend extrapolation of air passenger turnover with time (Fig. 2), the trend line fitting equation is:

$$
\mathrm{y}=4.8559 x-31.32
$$

In the equation, $y$ is air passenger turnover; $\mathrm{x}$ is the number of years since 1978. The trend extrapolation fitting correlation coefficient $\mathrm{R}^{2}$ of air passenger turnover with time is 0.897 , indicating that there is a significant correlation between the two, and the trend extrapolation prediction has high accuracy.

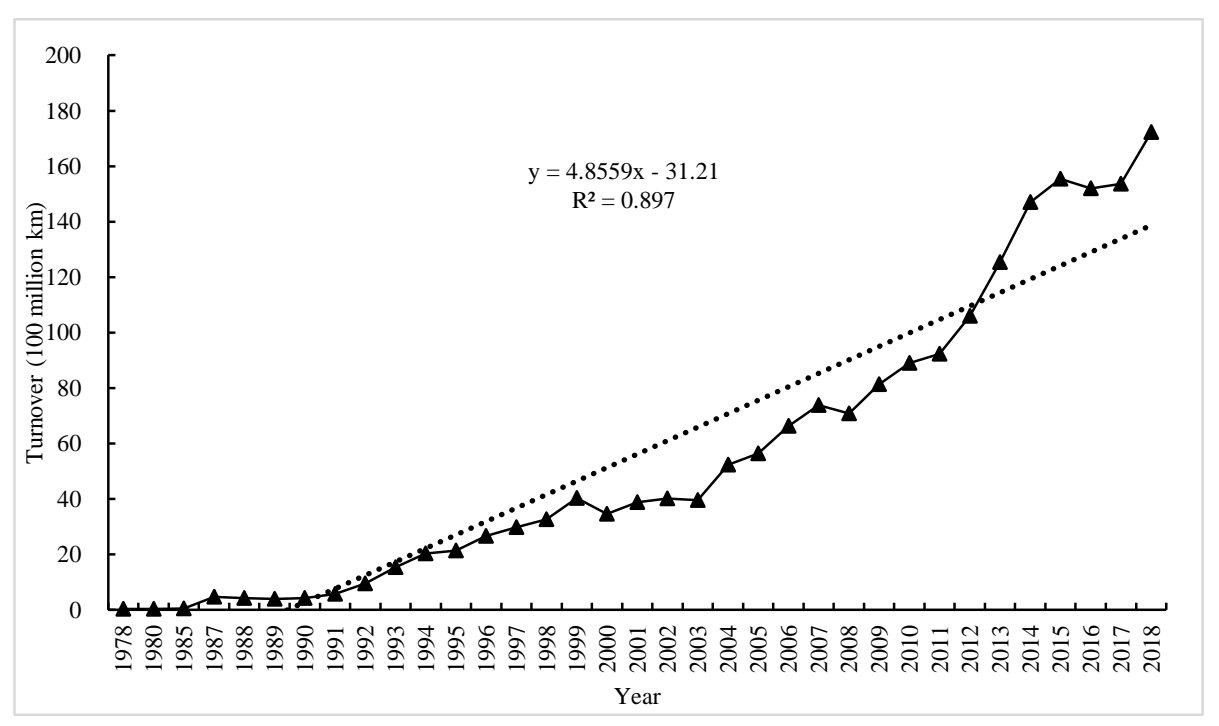

Figure 2. Trend of air passenger turnover

By substituting 2030 (52 years) and 2040 (62 years) into the trend line fitting formula of air passenger turnover, it can be obtained that the air passenger turnover in 2030 and 2040 is 22.13 billion person kilometers and 26.986 billion person kilometers respectively. By substituting the air passenger turnover in 2030 and 2040 into the regression relationship between air service employment and air passenger turnover in Fig. 1, it can get that the air transportation employment in 2030 and 2040 are 34166 and 42155 respectively. 


\subsection{Talent density analysis}

Due to the lack of investigation and statistics on talent density in the transportation industry in Yunnan Province, the prediction results to talent density in the national transportation industry were predicted with reference to the "demand prediction of transportation talents and development strategy of transportation education in 2015". As there is no air transportation type in the prediction results of specialized talents in the national transportation industry, the talent density was determined with reference to the national average level of maritime transportation industry based on the high demand for specialized talents in air transportation. According to the research results, the specialized talent density in maritime transportation in $1997,2005,2010$ and 2015 was $56.2 \%, 61.0 \%, 63.5 \%$ and $65.0 \%$ respectively, and the talent density showed a steady growth trend. Referring to the talent density in maritime transportation and its change trend, the talent density in Yunnan air transportation in 2018, 2030 and 2040 is 67\%, $75 \%$ and $80 \%$ respectively.

\subsection{Talent demand prediction}

By substituting the prediction results of employment and talent density in Yunnan transportation industry into the calculation formula of talent density method, the prediction results of talent demand in Yunnan transportation industry can be obtained. According to table 1, the total demand for talents in the air transportation industry in 2018, 2030 and 2040 was 18129, 25625 and 33724 respectively, showing a rapid growth.

Table 1. Prediction results of demand for specialized talents in Yunnan air transportation industry. Unit: People

\begin{tabular}{cccc}
\hline Years & Employment (people) & Talent density (\%) & Demand for talent (people) \\
\hline 2018 & 27058 & 67 & 18129 \\
2030 & 34166 & 75 & 25625 \\
2040 & 42155 & 80 & 33724 \\
\hline
\end{tabular}

Note: the employment data of air transportation industry in 2018 comes from "Yunnan statistical yearbook", and 2030 and 2040 are predicted values.

\section{CONCLUSION}

Based on the available statistical data, the quantitative prediction of the demand for specialized talent in the air transportation industry can be realized by using the talent density, regression analysis and trend extrapolation method. The forecast results showed that the demand for air transportation specialized talents would increase significantly in 2030 and 2040. Thanks to the rapid development of the air transportation industry, there were 10 colleges and universities above the college entrance examination qualification for air transport related majors in Yunnan Province by 2020, with an annual enrollment scale of about 2,500 people. The scale of talent training can basically meet the needs of air transportation industry development to supplement specialized talents. However, about $80 \%$ of the related majors are flight attendants with low threshold, which is not suitable for the actual demand. Therefore, it is necessary to gradually reduce the enrollment scale of flight attendant majors and expand the enrollment scale of non-flight attendant majors, thus meeting the needs of specialized talent structure for Yunnan air transportation industry development.

\section{ACKNOWLEDGMENTS}

This work was supported by The Science Research Fund Project of the Department of Education of Yunnan
Province - Study on the Regional Adaptability of Yunnan Transportation Talent Training (No.: 2020J1015) and the Special Project of Yunnan Province "Ten Thousand Talents Plan" Top Young Talents (No.: YNWR-QNBJ-2019-067).

\section{REFERENCES}

[1] Huang Weigang. Impact of Air Transportation Infrastructure on China's Industrial Structure Upgrading [D]. Tianjin: Civil Aviation University of China, 2020.

[2] Tang Jiaoyan. Development of Yunnan Transportation Vocational Education Based on Talent Demand [J]. Journal of Liaoning Higher Vocational Education. 2016, 18 (11): 14-16.

[3] Tang Jiaoyan. Demand Prediction of Specialized Talents in Yunnan Transportation Industry [J]. Western Transportation Technology, 2015 (6): 95-97.

[4] Hu Wei, Shi Weiping. Retrospect and Prospect of Research on Talent Demand Prediction of Vocational Education in China [J]. Education and Occupation, 2017 (13): 13-17. 
[5] Yan Xianliang, Gao Rongjin. Transportation Talent Prediction and Planning [R]. Beijing: Talent Planning Office of the Ministry of Communications, 1985.

[6] He Qianqian. Construction Status and Development Demand Prediction of Transportation Modernization Talent Team in Henan Province [J]. Science and Technology and Innovation, 2018 (7): 29-32.

[7] Jiang Yanqiao, Yu Siqin, Gu Jianguo. Demand Prediction of Transportation Specialized Talents and Development Strategy of Transportation Education in 2015 (Part I) [J]. Research on Transportation Higher Education, 2000 (3): 5-9.

[8] Department of Personnel and Labor of the Ministry of Communications, Department of Science, Technology and Education of the Ministry of Communications, Research Institute of Science of the Ministry of Communications. Research on Human Resource Guarantee and Intellectual Support Strategy for Transportation Development [Z]. 2005-10.
[9] Yu Yang, Liu Shuyan. Analysis and Prediction of Transportation Talents Based on System Dynamics [J]. China Water Transportation (Theoretical Edition), 2006, 08: 190-191.

[10] Ren Xinhui, Tang Shaoyong. Prediction of Air Passenger Transportation Demand in China - Based on the Combined Model of Econometrics and System Dynamics [J]. Transportation Research, 2015, 1 (1): 92-98.

[11] Guo Zixue, Cheng Tao, Zhang Yahui. Demand Prediction of Logistics Talents in Hebei Province Based on Fuzzy Combination Prediction [J]. Journal of Hebei Agricultural University (Social Science Edition), 2019, 21 (1): 125-129.

[12] He Zhen, Liu Chao. Optimization of Talent Demand Prediction for Vocational Education Planning [J]. Modern Education Management, 2021 (1): 85-91. 